\title{
Vorbemerkungen zum zweiten Teile
}

Während die zweite Abteilung der Kirchengeschichte im Druck war, ist Th. Mommsen durch den Tod von der Arbeit abgerufen. Ich habe nach dem bis zum Schluß fertig vorliegenden Manuscript des Textes und des Apparats die Correctur besorgt, auch die Collation des Palatinus 822, die G. Mercati mit unermüdlichem und stets hilfreichem Fleiß in die Druckbogen eintrug, nach den von Mommsen aufgestellten Grundsätzen dem Apparat einverleibt. Die Bibelstellen sowie die Entlehnungen der griechischen Kirchenhistoriker aus Rufin $\mathrm{X}$. XI sind von mir nachgewiesen.

Außer den zu Beginn von Buch I aufgeführten Handschriften hat Mommsen für den Text von Rufins Buch X und XI benutzt:

$$
L=\text { Lucca Capitularbibliothek } 490 \text {. }
$$

Im Apparat bedeuten $L^{a}$ und $L^{b}$ Lesung erster Hand vor und und nach der Correctur, $L^{1}$ und $L^{2}$ Lesung erster und zweiter Hand.

Die griechische Übersetzung, die zu großen Partien des elften Buches nach Mommsens Anordnung unter den Text gesetzt ist, stammt aus der zweiten Recension der Chronik des Georgios Monachos und ist von $\mathrm{De} B$ oor an Mommsen mitgeteilt.

Näheres werden die Prolegomena bringen, deren Manuscript von Mommsen selbst fertig gestellt ist. Der ursprbingliche Plan war, die Prolegomena dem ersten, die Indices dem zweiten Bande beizugeben. Er wurde aufgegeben, weil auf diese Weise die beiden Textbände unförmlich angeschwollen wären; auch ist es bequemer die Indices zu benutzen, wenn sie separat gebunden sind, So ist beschlossen, aus den Prolegomena und den Indices einen dritten Teil zu bieten, der bestimmt 1908 erscheinen wird.

Göttingen, November 1907

E. Schwartz. 


\section{$\bar{\zeta}$}

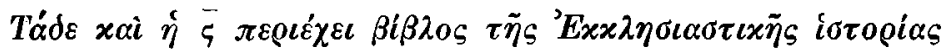

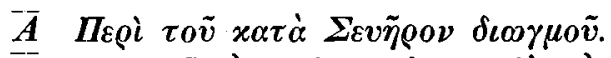

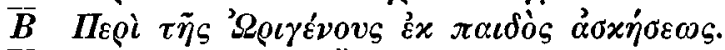

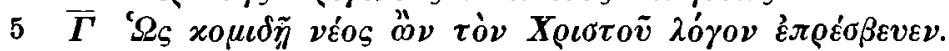

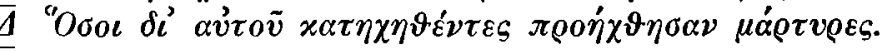

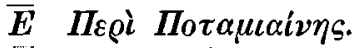

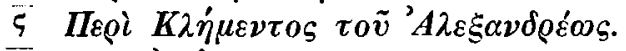

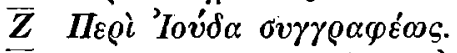

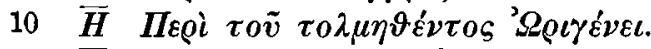

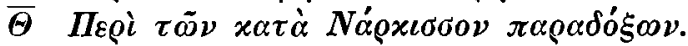

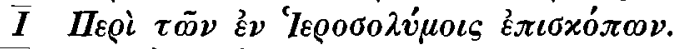

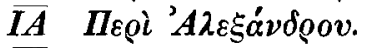

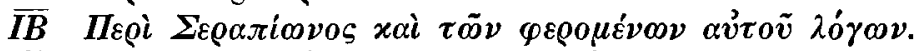

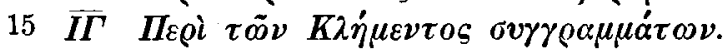

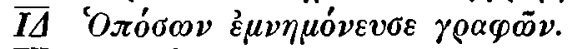

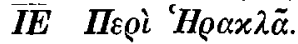

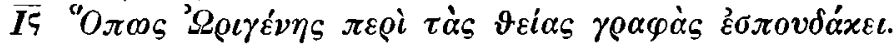

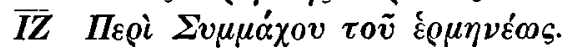

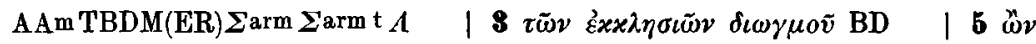

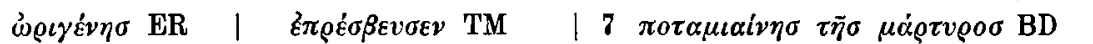

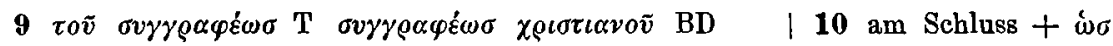

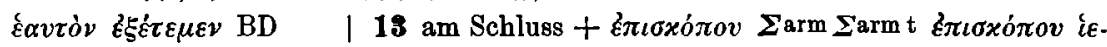

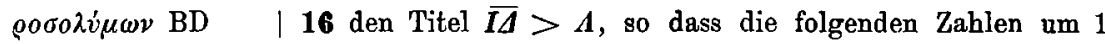

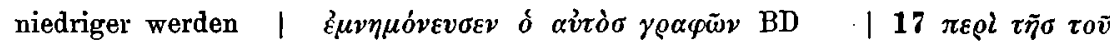

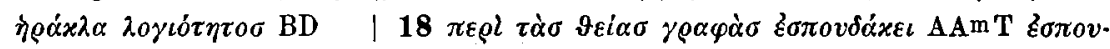

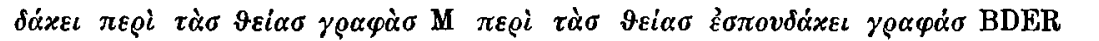

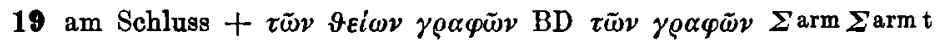

